\title{
Traducción de hápax legómena griegos y neologismos latinos en la traducción latina interlineal del Libro de Job de la Biblia Políglota Complutense*
}

José Francisco García Juan **

UNED

ORCID: 0000-0001-9494-0754

La Biblia Políglota Complutense (1514-1517), auspiciada por el Cardenal Francisco Jiménez de Cisneros (1436-1517), cuenta con traducciones interlineales para la columna de Septuaginta. Concebida como Biblia de estudio, el joven magister artium Juan de Vergara (1492-1557) realizó la interpretatio latina interlineal del libro de Job, que no se ha vuelto a publicar desde el s. XVI y de la que damos a conocer en este artículo los procedimientos de traducción usados con los hápax legómena griegos y los neologismos latinos acuñados por Juan de Vergara, como expresiones singulares de fidelidad al literalismo interlineal y de concreción interpretativa del texto bíblico.

Palabras clave: Biblia Políglota Complutense; Juan de Vergara; técnicas de traducción; sentido literal bíblico.

Greek "Hapax Legomena" and Latin Neologisms Translations in the Interlineal Latin Translation of the Book of Job in the Complutense Polyglot Bible.- The Complutensian Polyglot Bible (1514-1517), sponsored by the Cardinal Francisco Jiménez de Cisneros (1436-1517), reckons on interline translations for the Septuaginta column. Conceived as a Bible for research, the young man magister artium Juan de Vergara (14921557) accomplished the Latin interline interpretatio of the Book of Job, which has not been republished since the 16th Century and of which we make known in this article the

* Este artículo forma parte del Proyecto de Investigación: «Recepción y tradición de la Biblia en griego y latín: Edición y estudio de textos» (FFI2014-51910-P), cuyo investigador principal es José Manuel Cañas Reíllo (CSIC). La investigación que recoge forma parte del proyecto de tesis doctoral: «La traducción latina interlineal de los LXX en la Biblia Políglota Complutense: El libro de Job», codirigida por Matilde Conde Salazar y José Manuel Cañas Reíllo en el Departamento de Filología Clásica de la Universidad Nacional de Educación a Distancia (UNED).

j** jfcogjuan@gmail.com

Copyright: (9) 2017 CSIC. Este es un artículo de acceso abierto distribuido bajo los términos de una licencia de uso y distribución Creative Commons Attribution (CC-by) España 3.0. 
translation procedures used with the Greek "hápax legómena" and the Latin neologisms minted by Vergara are released, as singular expressions of fidelity to the interline literalism and the interpretative realization of the Bible text.

Keywords: Complutensian Polyglot Bible; Juan de Vergara; Translation Techniques; Biblical Literal Sense.

\section{La obra del CARdenal Francisco Jiménez de Cisneros}

En el siglo XII una mala lectura del Prólogo de Jerónimo al Pentateuco llevó en Occidente a postergar el estudio de las lenguas originales de la Sagrada Escritura, como lecturas falseadas por los judíos'. A la vez el desarrollo de la Escolástica, con su marcado carácter logicista, propició la desatención a la teología bíblica positiva en favor del método dialéctico.

El Renacimiento trajo de nuevo el griego y el hebreo originales de los textos bíblicos al interés de los sabios. El humanismo y los studia humanitatis se distanciaron de la tradición medieval que consideraba Vulgata como versión auténtica de la Biblia, hasta el punto de hacer sospechoso al texto hebreo de haber sido modificado por los rabinos donde discrepaba de Vulgata, y que despreciaba a la Septuaginta por cismática. El humanismo renovó una lectura bíblica histórico-literal que precisaba del conocimiento del hebreo y el griego ${ }^{2}$.

La redditio ad fontes rerum impulsó el trabajo de los humanistas, que aplicaron el método filológico a todos los ámbitos del saber, y por último también a la Biblia. Lorenzo Valla (1406-1457) con sus Annotationes, publicadas en 1505 por Erasmo de Rotterdam (1466-1536), junto a

${ }^{1}$ El texto de Jerónimo: sicubi tibi in translatione uideor errare, interroga Hebraeos, diuersarum urbium magistros consule; quod illi habent de Christo, tui codices non habent. Aliud est, si contra se postea ab Apostolis usurpata testimonia probauerunt, et emendatiora sunt exemplaria latina quam graeca, graeca quam hebraea!; cf. R. WEBER, Biblia Sacra Vulgata [Stuttgart ${ }^{4} 1994$ ] pág. 4, líneas 43-46. Fue origen del aserto que propició el sofoco de los pocos focos de conocimiento del griego en Occidente: el texto bíblico latino es más fiable que el griego, y el griego más que el hebreo; $c f$. J. H. BENTLEY, Humanists and Holy Writ: New Testament Scholarship in the Renaissance (Princeton 1983) págs. 15-16, y C. Linde, How to Correct the Sacra Scriptura? Textual Criticism of the Bible between the Twelfth and Fifteenth Century (Oxford 2012) págs. 107-109.

${ }^{2}$ Bentley, Humanists, pág. 31; N. Fernández Marcos y E. Fernández Tejero, Biblia y humanismo. Textos, talantes y controversias del siglo XVI español (Madrid 1997) pág. 17. 
Antonio de Nebrija (1441-1522) con sus tres Quinquagenae, fueron los grandes humanistas que desde su perspectiva de gramáticos aplicaron el método filológico al texto bíblico. El cotejo de la versión bíblica Vulgata con la redescubierta Septuaginta para el mundo latino occidental, y las primeras publicaciones del texto bíblico hebreo, provocaron la estigmatización de la traducción Vulgata y el deseo de búsqueda del texto original inspirado ante la evidente corrupción de los textos que estaban entonces en circulación ${ }^{3}$.

El cardenal Francisco Jiménez de Cisneros (1436-1517) tuvo una posición privilegiada y gran interés por la reforma de la Iglesia, que dirigió hacia una renovación de la teología cristiana que bebiese de nuevo en el mismo manantial de las tres lenguas originales de la Escritura. Beber el río trilingüe de la Escritura se convirtió en norma de vida para los académicos complutenses ${ }^{4}$ :

Vt ipsa igitur originalia in promptu haberet quicumque diuinarum litterarum studiosus: possetque non solis riuulis esse contentus sed ex ipso fonte salientis aquae in vitam aeternam sitim pectoris extinguere (BPC, vol. I: f. 1r).

Nació de ello la mayor empresa humanístico-científica del Renacimiento español: la Biblia Políglota Complutense (1514-1517). Obra monumental que puede considerarse la primera gran obra científica filológica de la era moderna y la que sentó las bases para las ediciones críticas bíblicas posteriores ${ }^{5}$.

${ }^{3}$ Accedit: quod ubicumque latinorum codicum uarietas est: aut deprauatae lectionis suspitio (id quod librariorum imperitia simul et negligentia frequentissime accidere uidemus) ad primam scripturae originem recurrendum est (Biblia Políglota Complutense [en adelante BPC] vol. I: f. 1v $\mathrm{v}^{\mathrm{o}}$; L. LyNNE, Translating the Bible: from the 7th to the 17th Century (Aldershot and Burlington, Vt. 2004) págs. 121-123; L. GiL, «La columna griega de la Biblia Políglota Complutense», en La Biblia Políglota Complutense, coord. A. Alvar Ezquerra (Alcalá 2016) págs. 261-283: 266-268.

${ }^{4}$ F. Rico, El sueño del humanismo. De Petrarca a Erasmo (Madrid 1993) pág 130; A. SÁEnz-BAdillos, La Filología Bíblica en los primeros humanistas de Alcalá (Estella 1990) págs. 387-393.

${ }^{5}$ Como señaló B. WaLton en el prefacio a la Políglota de Londres (1652 signat. B.): Haec editio (Complutensis) quasi fundamentum erat super quo plura aedificarunt qui editiones praecipuas adornarunt, cf. M. Revilla Rico, La Políglota de Alcalá (Madrid 1917) pág. II. 
La Biblia Políglota Complutense reunió en un solo trabajo las tendencias filológicas del humanismo del $\mathrm{s}$. XV respecto al texto bíblico y a la vez inauguró una nueva época para los estudios bíblicos en la que el análisis profundo de los textos originales será el punto de partida. Los objetivos del estudio bíblico humanístico fueron ${ }^{6}$ :

a) La edición de textos bíblicos en las lenguas originales con traducción latina para los no versados en hebreo y griego;

b) La edición de un texto bíblico reconocido y autorizado (receptus);

c) La elaboración por parte de los teólogos humanistas de comentarios bíblicos más extensos que las simples notas marginales de antaño, y a la vez más acordes con las nuevas corrientes de interpretación literal de la Escritura que parte ahora inexorablemente de los textos originales.

La conocida como «obra del Cardenal», la Biblia Políglota Complutense, inspirada en la Hexapla de Orígenes, respondía al primer objetivo de la filología bíblica y humanística de la época y preparaba el camino para los dos siguientes.

La Políglota se imprimió en seis volúmenes: los cuatro primeros contienen el Antiguo Testamento y constituyen la editio princeps de Septuaginta; el volumen $\mathrm{V}$ contiene la editio princeps del Nuevo Testamento griego y aparato para su estudio; el volumen VI diversos aparatos para el Antiguo Testamento 7 . Los libros protocanónicos del AT aparecen en

${ }^{6}$ J. Trebolle Barrera, «La obra del Cardenal», en Anejo a la edición facsímil de la Biblia Políglota Complutense (Valencia 1987) págs. 21-24: 24; H. JeCHOVÁ, «La difussion de la connaissance de la Bible», en L'Époque de la Renaissance 1400-1600, vol. 1 L'avènement de l'esprit Nouveau (1400-1480), dirs. T. Klaniczay, E. Kushner y A. Stegmann (Budapest 1988) págs. 239-249: 243.

Revilla Rico, La Políglota, págs. 37-48; F. J. Norton, La imprenta en España 15011520 (Madrid 1997) pág. 75; M. ${ }^{\mathrm{a}}$ V. Spottorno, «The Textual Significance of Spanish Polyglot Bibles», Sefarad 62:2 (2002) págs. 375-392: 385. Cisneros murió en la villa de Roa el 8 de noviembre de 1517. Los encargados de pedir la aprobación papal para la puesta en venta de la Políglota no se cuidaron de ello inmediatamente y los ejemplares quedaron almacenados en Alcalá casi tres años, hasta que enterado León X, por un Motu proprio de 22 de marzo de 1520 y ex certa scientia aprobó la Políglota y mandó a los albaceas que fijaran el precio de los ejemplares y que los pusieran a la venta pública. Entretanto Erasmo de Rotterdam (1466-1536) publicó su primera edición del NT en 1516 y en Venecia en 1518 se publicó la edición del AT iniciada por Aldo Manuzio (1449-1515), con lo que el la 
tres columnas: la Vulgata latina, como fiel traducción del hebreo en la del centro, a un lado la del texto griego de los LXX con traducción latina interlineal y al otro la columna del texto hebreo. Para el Pentateuco se incluyeron una cuarta columna con el Targum de Onkelos y una quinta con su traducción latina. El impresor fue el maestro Arnaldo Guillermo de Brocario (1460-1523). En este trabajo nos centramos en la versión latina interlineal del texto de Septuaginta del libro de Job, que se encuentra en el vol. III de la Biblia Políglota Complutense ${ }^{8}$.

\section{La Políglota Complutense: Biblia de estudio}

Cuando el cardenal Cisneros fundó el embrión de la Universidad de Alcalá en 1498, el Colegio-Universidad San Ildefonso, quería que se aprendiera latín, griego y hebreo para volver a los Padres, podar la hojarasca del Escolasticismo y restaurar la Antigüedad cristiana. En las Constitutiones de dicho Colegio dio la mayor importancia al griego: quoniam lingua graeca

Políglota perdió su principalía; $c f$. J. L. Gonzalo SÁnCHEZ-Molero, (dir.), V Centenario de la Biblia Políglota Complutense. La Universidad del Renacimiento. El Renacimiento de la Universidad (Madrid 2014).

${ }^{8}$ Brocario, según la costumbre de los primitivos talleres de imprenta y de los talleres medievales de copistas, no paginó los primeros tres volúmenes, que sólo contienen las signaturas a registro, es decir, una designación por letras y números de cada uno de los cuadernillos en la que se refleja la estructura material de cada ejemplar impreso. Esta signatura servía para ordenar correctamente la secuencia de cuadernos que constituía cada volumen y hacía posible al dueño comprobar si el ejemplar estaba completo y correctamente encuadernado. El libro de Job comienza un folio antes de la signatura de registro Fff y se prolonga tres folios después de Iii iii, ocupando en total 45 folios. Viene precedido del prólogo de Jerónimo a su traducción latina de Vulgata (título equivocado en la Políglota, que dice secundum translationem LXX) y del que hizo también para su traducción del texto griego hexaplar (que equivocadamente titula secundum hebraicum, cuando corresponde realmente a secundum $L X X$ ), así como de un Argumentum. Cf. Revilla Rico, La Políglota, págs. 56-59; J. Martín Abad, «Cisneros y Brocar. Una lectura tipobibliográfica de la Políglota Complutense», Estudios Bíblicos 72:1 (2014) págs. 33-73: 49; más sobre ecdótica en esta época en: http://ecdotica.hypotheses.org/976/ (septiembre 2016); con ilustraciones de Biblia Políglota Complutense en J. MARTín ABAD, «La impresión y la puesta en venta de la Biblia Políglota Complutense», en La Biblia Políglota Complutense, coord. A. Alvar EzQuerra (Alcalá 2016) págs. 295-326; y en la misma obra con una descripción de cada volumen en GIL, «La columna griega de la Biblia Políglota Complutense», págs. 262-266. 
fons est et origo latine linguae et aliarum scientiarum. Mientras que la vieja universidad de Salamanca producía juristas, a la nueva se le encomendó la tarea de crear teólogos escriturarios, expertos en lenguas clásicas y orientales, que estuviesen en condiciones de depurar los Libros Sagrados y de acceder a sus fuentes. Para llevar a cabo la Políglota, Cisneros reunió una Academia de humanistas, que incluía hebraístas conversos ${ }^{10}$ :

La empresa fue laboriosa y magnífica como las que más. Exigía no sólo un príncipe poderoso, sino también un hombre de valor extraordinario para superar todas las dificultades que acompañaban una tarea tan grandiosa. Sin perder tiempo llamó a su presencia a los hombres más competentes en las citadas lenguas: Demetrio Cretense, griego de nacimiento, Antonio de Nebrija, Lope de Zúñiga y Fernando Núñez el Pinciano, profesores de griego y latín, cuyos escritos y obras eruditas están hoy día en las manos de todos; Alfonso, médico de Alcalá, Pablo Coronel y Alfonso Zamora, peritísimos en hebreo, que en tiempos pasados habían dirigido escuelas públicas entre los suyos, y en la actualidad profesaban la fe cristiana. De ahí que con razón los llamó Jiménez para tan importante proyecto que merecidamente encomendó a su capacidad, erudición y constancia ${ }^{11}$.

La Políglota Complutense tuvo una vocación didáctica desde el principio; estaba destinada especialmente a letrados y a todos aquellos que se interesaran por el estudio profundo de las Escrituras ${ }^{12}$ : «Sed omnibus in uniuersum sacrarum litterarum studiosis» (BPC, vol. V, Prologus ad $N T$ : f. 3r).

Cisneros declara su objetivo a León X en el Prologus: «Vt incipiant diuinarum litterarum studia hactenus intermortua nunc tandem reuiuiscere» (BPC, vol. I: f. 1r).

9 J. LóPEZ RuEdA, Helenistas españoles del s. XVI (Madrid 1973) págs. 18-23.

${ }^{10}$ M. Fernández Álvarez, La sociedad española del Renacimiento (Madrid ${ }^{2} 1974$ ) pág. 33; M. Andrés MarTín, La teología española en el s. XVI, vol II (Madrid 1976) pág. 21; T. JimÉNEZ CALVENTE, «Quidnam heres stupidusque manes? La Biblia en manos de los Grammatici: Antonio de Nebrija y otros eruditos complutenses», en La Biblia Políglota Complutense, coord. A. Alvar Ezquerra (Alcalá 2016) págs. 239-260: 246-249.

${ }^{11}$ A. Gómez de CAStro, De las hazañas de Francisco Jiménez de Cisneros, ed. de J. Oroz Reta (Madrid 1984) págs. 115-119.

${ }^{12} C f$. N. Fernández Marcos, «La Políglota Complutense en su contexto», en La Biblia Políglota Complutense, coord. A. Alvar EzQuerra (Alcalá 2016) págs. 231-238: 235, y GıL, «La columna griega de la Biblia Políglota Complutense», págs. 266-268. 
El latín es la lengua vehicular de la Políglota para que todos puedan acceder a la sinfonía coral lingüística del texto bíblico en sus textos fontales, haciendo accesible a todos el griego y el hebreo. Para los que no conocían el griego se publica en apéndice del vol. V el primer diccionario griego-latín del NT, Sap y Sir, Lexicon Grecum, precedido de una Introductio quam breuissima ad grecas litteras. El vol. VI se dedica enteramente a Apparatus, a modo de herramientas para el estudio de la Biblia hebrea: una gramática hebrea, diccionario hebreo / caldeo-latín. Otro de los instrumentos pedagógicos fueron las traducciones interlineales para cada libro de Septuaginta ${ }^{13}$ : «Neminemque esse cupimus: quem peregrinorum idiomatum difficultas absterreat a diuinorum librorum penetralibus adeundis» (BPC, vol. I: f. 1v).

Cisneros, con auténtica sensibilidad de humanista filólogo obvia la insuficiencia de las traducciones y las traducciones interlineales latinas facilitarán el acceso al original griego:

Atque haec imprimis. Quare cum uniuscuiusque idiomatis suae sint uerborum proprietates: quarum totam uim non possit quamtumlibet absoluta traductio prorsus exprimere: tum id maxime in ea lingua accidit: per quam os domini locutum est (BPC, vol. I: f. 1r).

\section{LA TRADUCCIÓN LATINA INTERLINEAL DE JUAN DE VERGARA}

No conocemos bien la aportación concreta de cada uno de los académicos complutenses a la Políglota, entre los que se encontraba el joven magister artium Juan de Vergara (1492-1557). Por su propio testimonio en el proceso inquisitorial que le acaeció en 1533, sabemos que la traducción latina interlineal de los libros sapienciales fue principalmente obra suya, aunque no puede descartarse también la participación de Hernán Núñez, el Pinciano, y López de Zúñiga ${ }^{14}$ :

${ }^{13}$ Sáenz-Badillos, La Filología Bíblica, págs. 387-393; Spottorno, «The Textual Significance», pág. 380.

${ }^{14}$ Revilla Rico, La Políglota, pág. 110; M. Bataillon, Erasmo y España, estudios sobre la historia espiritual del. s. XVI (México-Buenos Aires ${ }^{2} 1966$ ) pág. 460; SÁENZBadillos, La Filología Bíblica, pág. 194; A. Hamilton, «Los humanistas y la Biblia», en Introducción al humanismo renacentista, ed. J. KRAYE (Cambridge 1988) págs. 137- 
....e que esto pudo muy bien dezir este declarante como esperimentado enello por que de mas de aver trasladado este declarante en latin por mandado del señor cardenal don fray Francisco Ximenez [de Cisneros] la mayor parte dela filosofia e metafisica de Aristoteles noto destas faltas de expositores mucho numero de que començo a hazer este declarante un tratado e despues por mandado del dicho señor cardenal este declarante traslado de griego en latin por ynterpretaçion [sic] ynterlineal los probervios i sapiençia, eclesiastico y eclesiastes y job y otros tratados o libros dela sagrada escriptura donde noto lo mismo i todo esto es notorio a los que algo saben... ${ }^{15}$.

[...] Entre los convocados para la empresa se cuenta Juan Vergara. Según me dijo bastantes veces le encomendaron la interpretación de los Libros llamados vulgarmente Sapienciales. Reintegró en su antiguo texto muchos pasajes, que en la versión latina parecían difíciles ${ }^{16}$.

Una traducción interlineal es una traducción uerbum de uerbo que tiene la finalidad de reproducir el sistema de la lengua original en otra lengua, enfocando las estructuras léxicas y sintácticas de esta a la reproducción de la lengua original. Se emplea, sobre todo, para fines de estudio linguiístico. Este tipo de apoyos pedagógicos fue frecuente en la época renacentista en el ámbito escolar para el aprendizaje de lenguas por medio del uso de textos bilingües ${ }^{17}$. Si para entender detallada y exhaustivamente un texto hebreo, griego o latino es necesario traducirlo previamente, la traducción interlineal se muestra como el instrumento filológico que abre el acceso a un texto que está en una lengua distinta de la propia para el poco entendido en esa lengua. Es instrumento para que el lector pueda moverse por el texto bíbli-

157: 146; J. García Oro, El Cardenal Cisneros. Vida y empresas II (Madrid 1993) pág. 497; M. MenÉndez Pelayo, Historia de los heterodoxos españoles (Madrid ${ }^{6} 2006$ ) pág. 706; I. Pérez Martín, Las Bibliotecas del Doctor Juan de Vergara y de Alonso de Cortona (Madrid-Málaga 2008) pág. 18; GiL, «La columna griega de la Biblia Políglota Complutense», págs. 274-281.

${ }^{15}$ J. E. Longhurst, «Alumbrados, erasmistas y luteranos en el proceso de Juan de Vergara», en Cuadernos de la historia de España XXVIII (Buenos Aires 1958) págs. 102-165: 162-163; SÁenz-Badillos, La Filología Bíblica, pág. 327.

${ }^{16}$ Gómez de CAstro, Hazañas, págs. 115-119.

${ }^{17}$ N. G. Wilson, From Byzantium to Italy: Greek Studies in the Italian Renaissance (Duckworth 1992) págs. 10-11; C. NoRD, «El error en la traducción: categorías y evaluación», en Estudis sobre la traducció, ed. A. HuRTADo Albir (Castellón 1995) págs. 91-107: 92-93. 
co sin dificultades, para que la sinfonía bíblica de las tres versiones (textus hebreus Jobi, translatio greca LXX cum interpretatione latina; translatio Beati Hieronymi) llegue nítidamente al teólogo. Es interpretatio ('intermediación') en la mente de los complutenses, no translatio, otro riachuelo para llegar al manantial de la Palabra divina ${ }^{18}$.

En la Complutense es Vulgata, y no el texto hebreo -lengua que Juan de Vergara consta que por esas fechas no dominaba- el texto aglutinante: el primus inter pares. El texto griego editado es un texto ecléctico, que recoge lecturas de mss. conocidos junto con variantes muy antiguas, desconocidas hoy, lo que llevó a algunos a pensar que los complutenses acomodaron el texto griego al hebreo, como acusó Brian Walton en el Prólogo a su Políglota Londinense (1653-1657) ${ }^{19}$.

La traducción latina interlineal de Juan de Vergara se adapta perfectamente al literalismo propio de un trabajo de este carácter. El método ordinario consiste en ofrecer una palabra latina para cada palabra griega según había establecido Lorenzo Valla para la traducción bíblica, pues

${ }^{18}$ E. SÁnchez SALOR, «Las artes liberales y la Biblia. Gramática, retórica y filología», en La Biblia Políglota Complutense, coord. A. Alvar EzQuerra (Alcalá 2016) págs. 213227: 220; HiER. Ep. 106, 2.

${ }^{19}$ Sobre el texto hebreo subyacente al texto de Vulgata y el largo debate sobre el tipo de traducción presente en el texto griego, $c f$. E. FERNÁNDEZ TEJERO, «El texto hebreo», en Anejo a la edición facsímil de la Biblia Políglota Complutense (Valencia 1987) págs. 2532; M. Cimosa, Guida allo studio dela Bibbia greca (LXX) (Roma 1995) pág. 41; M. HARL, G. Dorival y O. Munnich, La Bible grecque des Septante. Du Judaïsme hellénistique au Christianisme ancien (Paris 2011) págs. 179, 201-222; T. M. LAw, Cuando Dios habló en griego. La Septuaginta y la formación de la Biblia cristiana (Salamanca 2014) pág. 80. Sobre el texto de Job de la columna griega de la Políglota, $c f$. Fernández Marcos, Filología bíblica y humanismo (Madrid 2012) págs. 113-127 («The Septuagint reading of the book of Job») y 261-272 («Greek sources of the Complutensian Polyglot»). B. WALTON consideraba, en general, el texto griego de las Políglotas lejano al de la genuina versión de los LXX y acordado con el texto hebreo: Noua enim et mixta est haec Versio, partim ex LXX, partim ex Origenis additamentis ex Theodotione, partim ex Aquilae, Symmachi, aliorumque interpretum, immo et commentatorum Graecorum uerbis confarcinata, ut hoc modo textui Hebraeo per columnas aptius responderet (In Biblia Polyglotta prolegomena specialia, vol. 2 [Cantabrigiae 1828] pág. 106); GIL («La columna griega de la Biblia Políglota Complutense», pág. 270) rechaza la posibilidad de que los complutenses corrigieran, en ocasiones, el texto griego -sobre el hebreo- en casos de discrepancia, habida cuenta de diferencias entre los textos de ambas columnas, lo que obliga a suponer que las concordancias y las discrepancias estaban en los códices que manejaron. 
la máxima literalidad en la reproducción del texto inspirado sorteaba el escollo de la inspiración en una traducción bíblica ${ }^{20}$.

En los ejemplos de nivel léxico que vamos a exponer mostramos cómo Vergara se esfuerza con frecuencia por reproducir en latín la lengua griega y cómo a la vez innova y traduce con gran libertad, en ocasiones, para concretar en latín el sentido literal bíblico y convertir la traducción interlineal en verdadera intermediación (interpretatio) entre el lector y el texto bíblico griego ${ }^{21}$.

En la Introductio quam breuissima ad grecas litteras del Lexicon Grecum se dice que la razón de preparar este diccionario ha sido la variedad de sentidos que admiten las palabras griegas, porque en las traducciones hay que escoger un solo significado entre otros posibles:

Illam cum interpretandi munus (ut ipsi nostis) breuissimis quibusdam et arctissimis terminis circunscriptum sit: non potuit interpres in ipso transferendi discursu nisi unico tantum significato unam dictionem explicare (BPC, vol. V, Lexicon Grecum, f. a).

$\mathrm{Y}$, si se olvidan los múltiples matices de los términos originarios, es posible que se cierre la posibilidad de acceder a los sentidos místicos y a las alegorías de la Escritura:

Tamen quia sepe numero sic usu uenire solet ut multe dictiones apud grecos sicuti et in reliquis contingit idiomatis multiplices sortiantur significatus: atque ex hac frequenti sermonis amphibolia nonnumquam reconditissimi sensus ad allegoriam et alios mysticos sacre scripture intellectus attinentes pendeant (BPC, vol. V, Lexicon Grecum, f. a).

También allí hay un catálogo de las herramientas léxicas usadas: «Polluce; Cyrillo; Suida; Greco Cornucopia; Moschopulo; Magno etymologico; Ammonio; et aliis id genus scriptoribus» (BPC, vol. V, Lexicon Grecum, f. a).

\footnotetext{
${ }^{20}$ Bentley, Humanists, págs. 51-53.

${ }^{21}$ Los principales estudios sobre las traducciones interlineales en F. J. FERNÁNDEZ Vallina y L. Vegas Montaner, «Lengua y literatura en las Biblias Políglotas españolas: traducciones latinas y modelos subyacentes», Sefarad 42:1 (1982) págs. 129-139: 135, y «El texto latino», en Anejo a la edición facsímil de la Biblia Políglota Complutense (Valencia 1987) págs. 53-60, y SÁenz-BADILlos, La Filología Bíblica, págs. 327-336.
} 
Aunque en lo referente a la Políglota Complutense uno de los académicos, Diego López de Zúñiga (+1531) famoso por su controversia con Erasmo de Rotterdam, afirmó: uetera non inmutanda ${ }^{22}$, podemos pensar que los complutenses eran conscientes de que estaban haciendo una nueva traducción latina de la Biblia, y que acometieron la labor antes como filólogos que como teólogos por tratar el texto bíblico como texto literario $^{23}$.

\section{TÉCNICAS DE TRADUCCIÓN}

Alonso Shökel afirma del texto hebreo de Job que ningún libro de la Escritura tiene tantas palabras que salgan una sola vez en toda la Biblia; a lo que se debe añadir la concisión de la frase, la fórmula elíptica, la riqueza y variedad de las imágenes ${ }^{24}$. Esta dificultad del texto hebreo ya la advirtió Jerónimo en el Prólogo a Job de Vulgata:

Obliquus enim et apud Hebraeos totus liber fertur et lubricus et quod Graeci rethores uocant schematismenos, dum qui aliud loquitur aliud agit, ut si uelis anguillam uel murenulam strictis tenere manibus, quanto fortius presseris, tanto citius elabitur (BPC, vol. III, Eee iiij(2)r).

Del Job griego podría decirse que también presenta un texto resbaladizo, por lo que resulta paradigmático para el estudio de las traducciones interlineales de Juan de Vergara. Juan de Vergara, como fidus interpres, que mantiene el literalismo como ley fundamental (pues en el texto inspirado: et uerborum ordo mysterium est [Hier. Ep. 57 I, 2]), traduce usando principalmente técnicas de traducción directa (traducción literal y préstamo), pero usando también en ocasiones técnicas oblicuas (adaptación y perífrasis), que corresponden a traducciones más libres (ad sensum) que garantizan la inteligibilidad del sentido literal del texto bíblico y el carácter intermediario de las interlineales y donde quizás, solo eventualmente,

${ }^{22}$ S. Aguadé Nieto, «La Biblia Políglota, los intelectuales y el poder», en La Biblia Políglota Complutense, coord. A. Alvar Ezquerra (Alcalá 2016) págs. 116-152: 119.

${ }^{23}$ SÁenz-Badillos, La Filología Bíblica, págs. 441-454.

${ }^{24}$ R. Lazcano, «La traducción del Libro de Job de Fray Luis de León», Religión y cultura LIII (2007) págs. 281-322: 308. 
propone las modificaciones a Vulgata que no hicieron los complutenses en la columna donde se la edita ${ }^{25}$. La Biblia es un texto inspirado, y el texto exige un respeto no sólo al sentido sino también a la forma. La necesidad de traducir en una traducción interlineal de uerbo ad uerbum (BPC, vol. I: f. 1v) llevará a Juan de Vergara a trasladar antes que a traducir, según la distinción de ambas cosas que hiciera Jerónimo de Huerta ${ }^{26}$.

En la traducción de los hápax legómena griegos y en la acuñación de neologismos latinos de la interlineal de Job, Vergara usa de estas técnicas de traducción ${ }^{27}$ :

- Traducción literal (de uerbo ad uerbum): traducción palabra a palabra. Se encuentra en traducciones hechas entre lenguas de la misma familia y cultura, pero muy especialmente en las traducciones bíblicas por el carácter inspirado del texto. Es el procedimiento más generalizado en la interlineal. El resultado a menudo suelen ser calcos o mímesis etimológica de la estructura interna de las palabras griegas en latín.

- Préstamo (transliteratio): propiamente es la no-traducción. Evoca en Septuaginta y en la interlineal el texto fuente hebreo. Hay préstamo puro (palabras que tal cual pasan del griego al latín,

${ }^{25}$ E. A. NIDA y C. R. TABer, The Theory and Practice of Translation (Leiden 1982) págs. 7-8; R. H. Chinchilla, «The Complutensian Polyglot Bible (1520) and the Political Ramifications of Biblical Translation», Livius 6 (1994) págs. 169-190; J. MundAY, Introducing Translation Studies, Theories and Applications (London-New York ${ }^{2} 2008$ ) págs. 55-58.

${ }^{26}$ «... diré qué sea traducir y en qué difiere de trasladar... trasladar en rigor significa propiamente mudar una cosa de un lugar a otro sin diferencia alguna... en larga significación se toma para traducir el sentido de la cosa escrita en otra lengua... Pero traducir en rigor con más estrecho significado es pasar una cosa de una parte a otra con mejoría... Porque trasladar (como he dicho) es mudar la misma cosa a otro lugar, o sacar palabra por palabra lo que está escrito, con las mismas líneas, colores y figuras lo que está pintado, sin ninguna falta o sobra: pero traducir es poner el mismo sentido, no rigurosamente palabra por palabra, sino con elegancia, claridad y provecho de la lengua en que se traduce de otra...», cita de Jerónimo de Huerta de 1624, en M. RodríguezPANTOJA, «Traductores y traducciones», en Los humanistas españoles y el humanismo europeo (IV Simposio de filología clásica), coord. F. MoYA DEL BAÑo (Murcia 1990) págs. 91-124: 109.

${ }^{27}$ L. Molina y A. Hurtado Albir, «Translation Techniques Revisited: A Dynamic and Functionalist Approach», Meta XLVII: 4 (2002) págs. 498-512. 
algunas incluso desde el hebreo sin adaptación alguna fonética o morfológica) o préstamo con adaptación (palabras que se adaptan al sistema fonético y morfológico latino).

- Adaptación (comparatio): este procedimiento es el límite extremo de la traducción, por cuanto el traductor cambia un elemento cultural de la lengua griega por otro propio de la lengua latina con el que mantiene equivalencia cultural. Las palabras traducidas mediante adaptación constituyen las interpretaciones más originales del texto bíblico de la traducción interlineal.

- Perífrasis (paraphrasis) o ampliación lingüística: procedimiento usado para hacer posible la traducción literal íntegra al latín de lo que en griego es muy conciso. Consiste en traducir un término por dos o más, traduciendo literalmente cada formante griego.

TRADUCCIÓN DE LOS HÁPAX LEGÓMENA GRIEGOS EN LA TRADUCCIÓN INTERLINEAL LATINA DEL LIBRO DE JOB

Entre las palabras que podemos denominar hápax en el texto griego de Job hay tanto hápax legómena absolutos en todo el léxico griego como hápax legómena solo bíblicos. Entre ellos hay préstamos hebreos transliterados en Septuaginta, cuya presencia se explica generalmente por ignorancia de los traductores o porque provienen a su vez de hápax legómena hebreos. Para algunos su supervivencia en el texto bíblico griego se debe a que los traductores de Septuaginta habrían pretendido respetar el carácter técnico de algunos términos de especial valor religioso para los que no existía equivalente griego; para otros se debe a que lo que parecía mejor dicho en hebreo no se habría logrado decir igual en griego; finalmente, otros piensan que es un modo de ornar la traducción y guardar vestigios de su base hebrea. De hecho, la revisión de Septuaginta de Teodoción se distinguió particularmente por la presencia de préstamos transliterados que siguen presentes en el texto griego de la Políglota de Alcalá. Los hápax propiamente griegos podrían tener origen en idiotismos alejandrinos de un texto que no fue traducido primeramente para la lectura sinagogal sino para un público y ámbito más general ${ }^{28}$.

\footnotetext{
${ }^{28}$ Law, Cuando Dios habló en griego, pág. 80.
} 
La traducción latina en la interlineal de estos hápax es una de las mayores expresiones de concreción de sentido y novedad interpretativa de la Políglota. Los exponemos en la forma concreta en que aparecen en la columna griega de la Políglota junto a la versión Vulgata de la Políglota, cuando existe, y también reproducimos el versículo en el que aparecen para que se puedan apreciar sinópticamente la versión griega con la interlineal latina y Vulgata cuando resulta pertinente ${ }^{29}$.

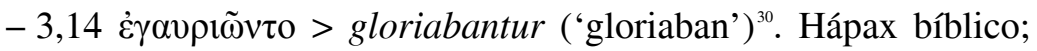
traducción literal a partir del sentido de $\alpha \gamma \alpha ́ \omega$ - $\alpha \gamma \alpha v \rho i ́ \alpha \mu \alpha$.

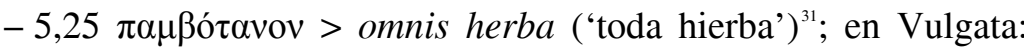
herba. Hápax absoluto; traducción mediante perífrasis que reproduce en un calco equivalente los elementos del compuesto griego.

- 12,4 $\chi \lambda \varepsilon v ́ \alpha \sigma \mu \alpha>$ subsannationem ('objeto de burla') 32. Hápax bíblico; traducción literal; se aprecia una equivalencia parcial entre el sufijo griego y el latino.

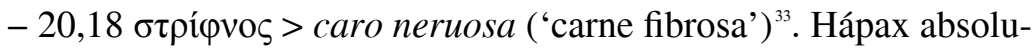
to; traducción mediante perífrasis descriptiva del vocablo griego.

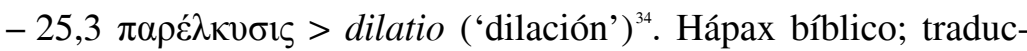
ción literal; se aprecia equivalencia entre el sufijo griego y el latino: $-\sigma \iota \varsigma>-t i o$.

${ }^{29}$ Harl, Dorival y Munnich, La Bible grecque des Septante, pág. 261; para las grafías hebreas de los hebraísmos, $c f$. J. M. CAÑas Reíllo, «Libro de Job», en La Biblia Griega: Septuaginta. III. Libros poéticos y sapienciales, eds. N. Fernández MarCos y M. ${ }^{a}$ V. Spottorno Díaz-Caro (Salamanca 2013) págs. 413-497.

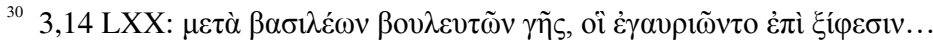

Interlineal: cum regibus, consiliariis terre, qui gloriabantur in gladiis...

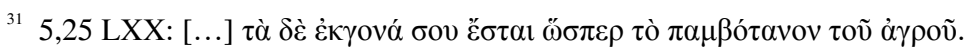

Interlineal: $[\ldots]$ at genimima tua erunt tanquam omnis herba agri.

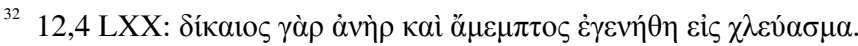

Interlineal: Iustus enim vir et integer factus est in subsannationem.

${ }_{33}^{3} 20,18$ LXX: [...]

Interlineal: [...] sicut caro neruosa que non manditur, que non bibitur.

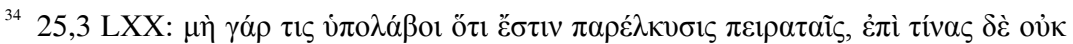

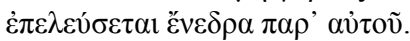

Interlineal: Non enim aliquis putet quod est dilatio predonibus, super quos autem non ueniet insidiatio ab eo? 


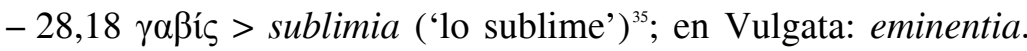
Hápax absoluto; el término griego es una transliteración del hebreo גביש 'cristal', 'piedra preciosa'"

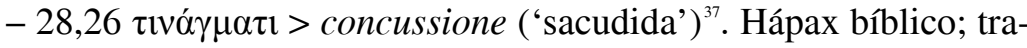
ducción literal; se aprecia equivalencia entre el sufijo griego y el latino: $-\mu \alpha>-$ tio.

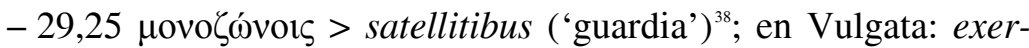
citu. Hápax bíblico que también aparece en 4Re 5,2. Vergara no traduce los dos formantes del compuesto griego, sino que los reduce a un único término latino mediante el cual consigue, por adaptación, reflejar el matiz de soldado ligeramente armado con satelles; Vulgata, sin embargo, recurre a la generalización del término con exercitus.

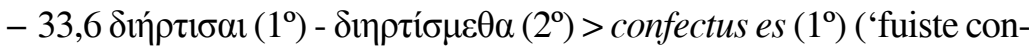
formado') - perfecti sumus ( $2^{\circ}$ ) ('fuimus acabados'); en Vulgata: $\mathrm{fe}$ cit $\left(1^{\circ}\right)$ - formatus sum $\left(2^{\circ}\right)$. Hápax absoluto; traducción literal en la que se aprecia la adaptación del preverbio para traducir el matiz más adecuado dentro del versículo al igual que ocurre en Vulgata:

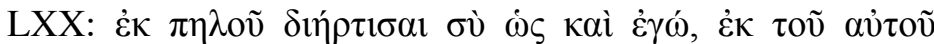
$\delta i \eta \rho \tau i ́ \sigma \mu \varepsilon \theta \alpha$.

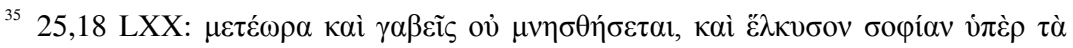

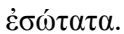

Interlineal: Excelsa et sublimia non conmemorabuntur, et trahe sapientiam super intima.

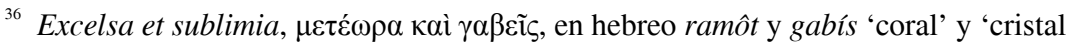
de roca', $c f$. M. H. Pope, Job (New York ${ }^{7} 1980$ ) pág. 204; también puede consultarse

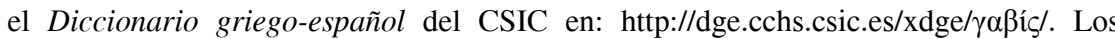
traductores no lo entendieron bien, como comenta Diego de ZúñIGA, In Iob commentaria (Roma 1591, accesible en: https://galileo.ou.edu/exhibits/commentary-book-job/ [última consulta, septiembre 2016]) pág. 408: Ita etiam Graeci transferunt, sed ramoth et gabis, quae hi classici interpretes excelsa et eminentia reddunt, omnes Hebraei Chaldaeum sequentes, lapides quosdam pretiosos esse dicunt et ita coralia et unionem quidam interpretantur, alii smaragdos et gemmas.

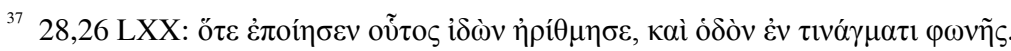

Interlineal: Quando fecit hic uidens numerauit et uiam in concussione uocis.

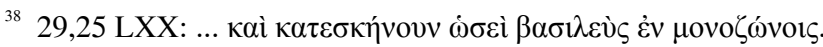

Interlineal: ... et in tabernaculo eram sicut rex in satellitibus. 
Interlineal: De luto confectus es tu sicut et ego, de eodem perfecti sumus.

Vulg.: Ecce et me sicut et te fecit deus: et de eodem luto ego quoque formatus sum.

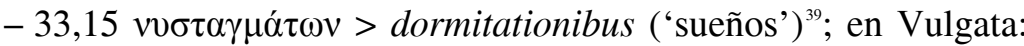
dormiunt. Hápax absoluto; traducción literal; se aprecia equivalencia entre el sufijo griego y el latino.

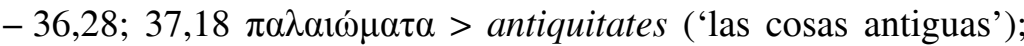
37,21 $\pi \alpha \lambda \alpha \iota \omega ́ \mu \alpha \sigma \mathrm{v}>>$ antiquitatibus ('los tiempos antiguos') ${ }^{40}$. Hápax absoluto; traducido por adaptación por un término latino clásico.

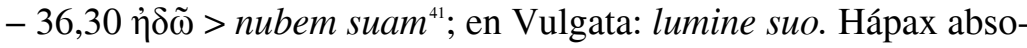
luto; traducción literal mediante perífrasis de $\eta \dot{\gamma} \tilde{\omega}$, transliteración del hebreo אורו 'su brillo', 'su resplandor', leído como אודו 'su vapor', 'su neblina'. No se trata de una nube cualquiera, sino de la nube divina que a la vez vela y revela a Dios, por ello la aparente contradicción entre la interlineal y Vulgata, y el mantenimiento del hebraísmo en $\mathrm{LXX}^{42}$.

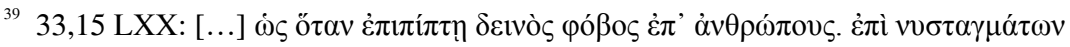

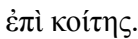

Interlineal: [...] sicut cum incidat grauis timor super homines in dormitationibus in cubili.

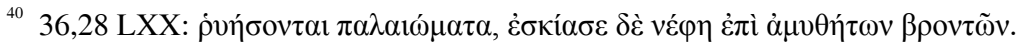

Interlineal: Fluent antiquitates, inumbrauerunt autem nubila in indicibilibus tonitruis.

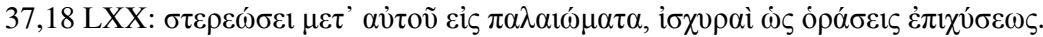

Interlineal: Firmabit cum eo in antiquitates, fortes ut inspectiones infusionis.

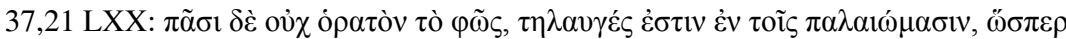

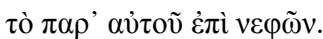

Interlineal: Omnibus autem non uisibile lumen, lucidum est in antiquitatibus sicut ab eo in nebulis.

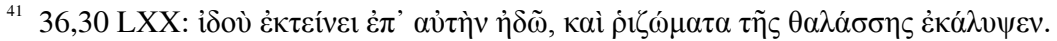

Interlineal: ecce extendit super illud nubem suam, et fundamenta maris abscondit.

${ }^{42} \eta \dot{\delta} \tilde{\omega}$, hebraísmo de discutida interpretación y variada traducción: "Ecce extendet super eum Edo". Symmachus uero, "extendit super eum lumen suum". Alia autem exemplaria pro Edo, Arcum habent. Si igitur homo considerauerit, quemadmodum, nubium collectione facta, tenuiores inter eas feriendo, radii solares arcum efficiant (qui uulgo, Iris appelatur) opificis sapientiam admirabitur, qui in nubium condensatione commodum et fructuosum pluie usum hominibus operatur, in laxitate autem et raritate earum, ad solatium incolarum terrae, facit ut arcus appareat, quia non amplius diluuio 
- 37,12 $\theta \varepsilon \varepsilon \beta 0 v \lambda \alpha \theta \omega ́$ > gubernaculis ('gobernalles') ${ }^{43}$; en Vulgata: uoluntas gubernantis. Hápax absoluto; transliteración del hebreo תחבולתו 'su dirección', traducido conforme a Vulgata.

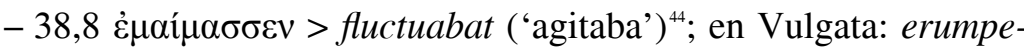
bat. Hápax bíblico; traducción literal a partir del sentido del considerado sinónimo $\mu \alpha \iota \mu \alpha \omega^{45}$.

- 38,14 $\lambda \alpha \lambda \eta \tau$ tóv > loqui potens ('capaz de hablar') "46; en la traducción hexaplar de Jerónimo: famosum ${ }^{47}$. Hápax bíblico: traducción por perífrasis interpretativa de los componentes griegos ${ }^{48}$.

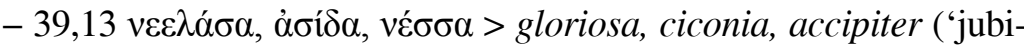
losa', 'ciguieña', 'halcón'); en Vulgata: penna struthionis, herodii, accipitris. Los tres términos griegos son transliteración de palabras

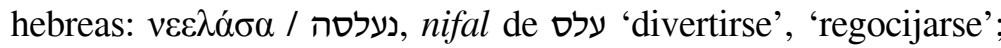

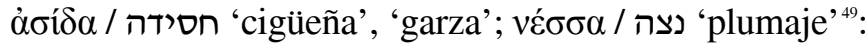

eos inundaturus est, sed juxta promissum suum, immoderatum aquarum impetum et uim cohibet (Olimpiodoro, en Catena Graecorum Patrum in Beatum Job, Patrick Young, Heracleensis Nicetas, ex Typographio regio [Londini 1637]. Niceta Heracleae metropolita ex duobus mss. bibliothecae bodleianae, codicibus, Graece nunc primum in lucem edita et Latine versa, opera et studio Patricii Iunii, pág. 525); cf. CAÑAS RÉ́lLo, «Libro de Job», pág. 485 nota $\mathrm{f}$, donde para el término griego se recoge también el significado de 'arco iris',

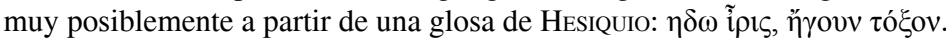

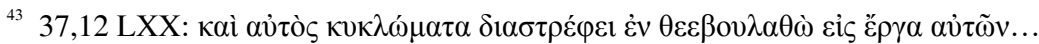

Interlineal: Et ipse circuitus peruertit in gubernaculis in opera eorum...

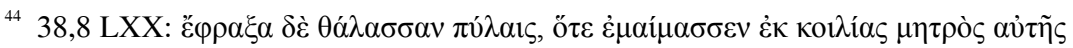
$\dot{\varepsilon} \kappa \pi \mathrm{\rho} \varepsilon v 0 \mu \mu \dot{\varepsilon} \vee \eta$

Interlineal: Conclusi autem mare portis quando fluctuabat de uentre matris sue procedens.

${ }^{45}$ H. G. Lidell, R. Scott y H. S. Jones, A Greek-English Lexicon ([abrev. LSJ] Oxford 1996) pág. 1073; T. Muraoka, A Greek-English Lexicon of the Septuagint (Louvain 2009) pág. 438.

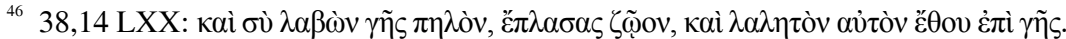

Interlineal: Et tu accipiens terre lutum formasti animal, et loqui potens ipsum posuisti super terram.

${ }^{47}$ C. P. CASPARI: Das Buch Hiob in Hieronymus's Übersetzung aus der alexandrinischen Version: Nach e. St. Gallener Handschrift, saec. VIII (1, 1-38, 16) (1893) pág. 108.

${ }^{48}$ LSJ, pág. 1026; MuraoKa, A Greek-English Lexicon of the Septuagint, pág. 423.

${ }^{49}$ En este versículo se habla de tres animales: struthio, herodius et accipiter, 'avestruz, cigüeña y halcón’, pero solo Vulgata los menciona explícitamente. En efecto, cuando se 
Interlineal: Ala eorum qui delectantur gloriosa, si comprehenderit ciconia et accipiter.

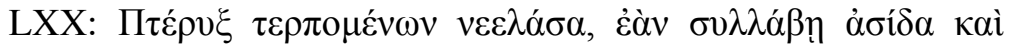

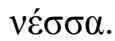

Vulg.: Penna struthionis similis est pennis herodii et accipitris.

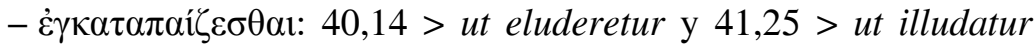
('para ser ridiculizado'). Hápax absoluto; Vergara traduce literalmente la raíz griega, pero, habida cuenta de la sinonimia de eludo e illudo, abandona la literalidad en la traducción del prefijo:

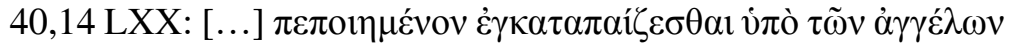

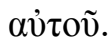

Interlineal: [...] factum ut eluderetur ab angelis eius.

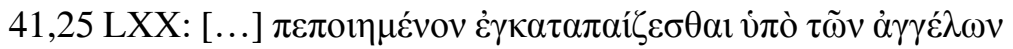
$\mu$ ov.

Interlineal: [...] factum ut illudatur ab angelis meis.

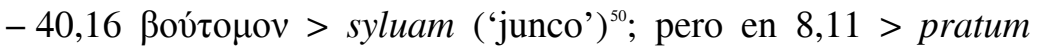

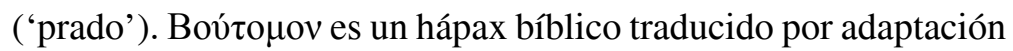
al contexto. En la interlineal aparece traducido por un término de sentido más genérico que en el vocablo griego, cuyo sentido

habla del «avestruz», los LXX traducen el hebreo «renanim», struthio (cuya raíz es «ranan»,

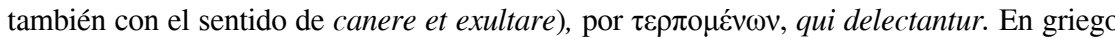
$\nu \varepsilon \varepsilon \lambda \alpha \dot{\sigma} \sigma \alpha$ es transliteración del vocablo hebreo con la raíz de «divertirse», «regocijarse», de ahí la traducción en la interlineal por gloriosa, que podemos entender como «jubilosa», «alegre», «gloriosa». Con ello la determinación del primer animal queda desfigurada y

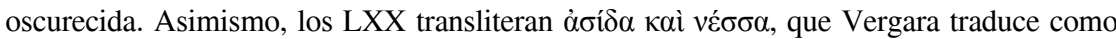
ciconia et accipiter. Asida iuxta Aquilam, erodius est, vel ciconia (OlimpIODORo, Catena Graecorum Patrum, pág. 559). Quod "herodium" nominat, in Hebraeo "hasida", quod nomen LXX uiri in sua uersione omiserunt. [...] Herodium autem putat Suidas aut ciconiam

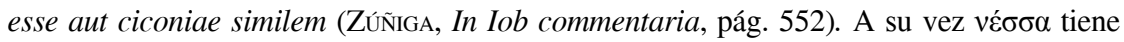
el sentido de «plumaje», «plumas» en Lv 1,16 y Ez 17,3.7 (PoPE, Job, pág. 308). Quod accipitrem uertit, est in Hebraeo "netsa" quod nomen etiam Graeci praetermiserunt. Consentiunt omnes Hebraei accipitrem significare et quidam Hebraeus illum esse tradit quem Hispane uocamus azor/asor (ZúÑIGA, In Iob commentaria, pág. 552).

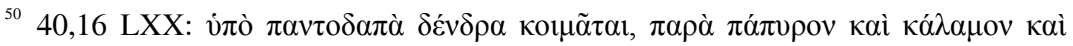

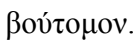

Interlineal: Sub omnigenas arbores dormit, iuxta papyrum et calamum et syluam. 
específico es el de carex riparia ${ }^{51}$. Así se encuentra en la traducción hexaplar de Jerónimo, en 40,16: caricem $^{52}$; aunque en 8,11 empleó: iuneus ${ }^{53}$.

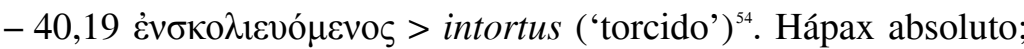

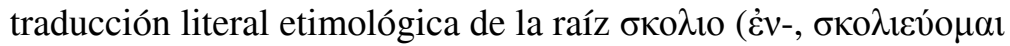
$>$ in-, torqueo $)^{55}$.

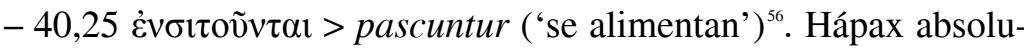

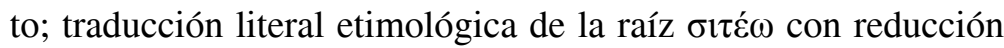
del prefijo griego.

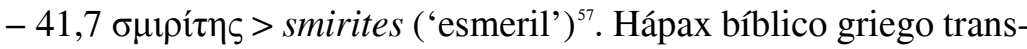
literado al latín.

En la interpretatio latina de los hápax legómena griegos del Libro de Job se advierte el literalismo absoluto del trabajo de Juan de Vergara y la voluntad de que sea intermediación que facilite el acceso a la versión griega de los LXX. Sobremanera abundan las traducciones literales, cuando es posible etimológicas, que caracterizan el trabajo de Juan de Vergara, y, cuando esto no es posible, usa de las otras técnicas de traducción, para que el lector pueda sortear el escollo de unos vocablos griegos muy raros y alcanzar por esta interpretatio una lectura literal del texto bíblico griego.

${ }^{51}$ LSJ, págs. 326-327.

${ }^{52}$ PL 29: col. 110B.

${ }^{53}$ Caspari, Das Buch Hiob, pág. 61.

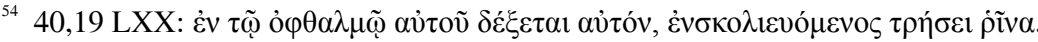

Interlineal: In oculo eius accipiet eum, intortus perforabit narem?

${ }^{55}$ La traducción coincide con el sentido ofrecido por el Diccionario griego-español

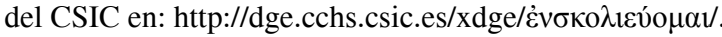

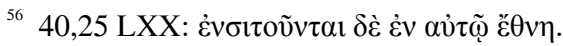

Interlineal: Pascuntur autem in eo gentes?

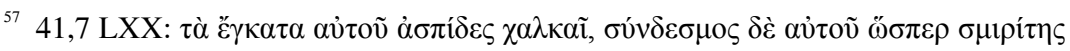
$\lambda i ́ \theta$ os.

Interlineal: Interiora eius scuta enea, coniunctio autem eius sicut smirites lapis. 
NeOLOGISMOS LATINOS EN LA TRADUCCIÓN LATINA INTERLINEAL DE JoB

Con la traducción interlineal el lector es invitado a un trabajo de retraducción. Sin embargo, en un texto como el libro de Job: «las zonas de intraducibilidad están diseminadas en el texto, y hacen de la traducción un drama y del deseo de una buena traducción un desafío» ${ }^{58}$. El desafío llega hasta el extremo de acuñar neologismos latinos, con procedimientos fácilmente comprensibles, cuando no se tiene la palabra exacta en latín para trasladar la palabra griega.

- 12,6 Ë $\tau \alpha \sigma i \varsigma>$ secutatio ('examen'). Traducción mediante adaptación que imita la estructura de la palabra griega desde la raíz de sequor. Jerónimo en su traducción hexaplar emplea: inquisitio ${ }^{59}$. No está recogida en ningún léxico latino.

- 15,33 ö $\mu \varphi \alpha \xi>$ acresta ('agrazones'). Traducción literal que forja un neologismo por contaminación de acer y agrestis. En la traducción hexaplar de Jerónimo: ииа асеrua ${ }^{60}$.

- 20,17 $\alpha$ ’ $\mu \varepsilon \lambda \xi i v>$ mulsionem ('cuajada'). Traducción literal a partir del tema de perf. del verbo mulgeo, en la que imita, mediante calco y analogía, el procedimiento derivativo griego: del verbo

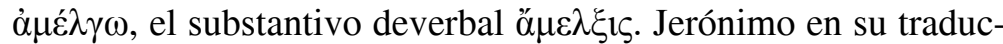
ción hexaplar emplea: mul, corregido por manos posteriores por los vocablos más clásicos: mulcturam / mulctram $^{61}$.

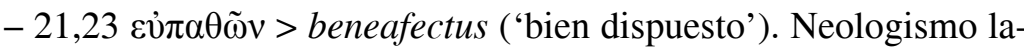
tino por traducción literal con mímesis etimológica del compuesto griego. No tiene precedentes constatados.

${ }^{58}$ P. Ricoeur, Sobre la traducción (Barcelona 2005) pág. 22.

${ }^{59}$ Caspari, Das Buch Hiob, pág. 67. Muraoka (A Greek-English Lexicon of the Septuagint, pág. 295) traduce el substantivo griego por investigation.

${ }^{60}$ CASPari, Das Buch Hiob, pág. 73; Para el origen del término $c f$. Du CANGE et alii, Glossarium mediae et infimae latinitatis. Éd. augm. (Niort: L. Favre, 1883-1887) t. 1, col. 147, en: http://ducange.enc.sorbonne.fr/agresta. Aquí viene recogido como sustantivo ex Italico «agresto» con el sentido de «aigret», acidulus. Remite a agrascum, Hispan. «agraz», recogido en Raynouardi Lexic. Roman. vol. I, pág. 34, núm. 5.

${ }^{61}$ CASPARI, Das Buch Hiob, pág. 80. La forma de este sustantivo ya se documenta con otro sentido en el s. XIV, $c f$. DU CANGE, Glossarium, t. 5, pág. 539, col. b. (en: http:// ducange.enc.sorbonne.fr/mulsio). 
- 26,5 $\mu \alpha \omega \theta \eta ́ \sigma o v \tau \alpha 1>$ mutrientur ('serán paridos'); en Vulgata: gemunt. Aquí posiblemente nos encontramos ante un error tipográfico de la Políglota y debiera decir: matrientur ${ }^{62}$. Se trata de una traducción literal que imita incluso el carácter deponente del verbo griego. Concreta el tipo de gemido, pues se trata de gemidos por parto de gigantes. Vulgata no matiza y emplea un verbo más genérico:

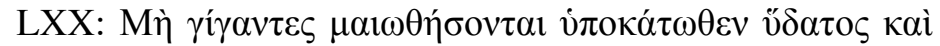

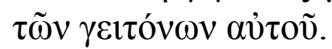

Interlineal: Numquid gigantes mutrientur sub aqua et uicinis eius?

Vulg: Ecce gigantes gemunt sub aquis: et qui habitant cum eis.

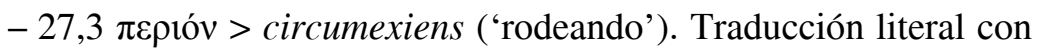
mímesis etimológica del primer preverbio griego. La forma no está atestiguada en léxico latino alguno, semánticamente es sinónimo de circumeo.

- 30,4 $\alpha \lambda \lambda \mu \alpha\left(1^{\circ} 2^{\circ}\right)>$ auronem $\left(1^{\circ}\right)$, auro $\left(2^{\circ}\right)$. Traducción mediante adaptación de un lema griego $\alpha \lambda \lambda_{\mu} \mu v$, que carece de equivalente latino. El término griego significa 'verdolaga', atriplex Halimus $^{63}$. Jerónimo en la traducción hexaplar emplea: cortices arborum $\left(1^{\circ}\right)$, radix herbarum $\left(2^{\circ}\right)^{64}$ :

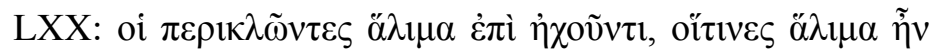
$\alpha \hat{\tau} \tilde{\omega} \nu \tau \grave{\alpha} \sigma \tilde{\tau} \tau \alpha$.

${ }^{62}$ La forma del verbo puede tener origen en matresco, con forma deponente que imita el griego $\mu \alpha \omega \theta \eta ́ \sigma o v \tau \alpha 1$. En ZúÑIGA, In Iob commentaria, pág. 387: obstetricabuntur, id est, parturiunt.

${ }^{63}$ LSJ, pág. 65.

${ }^{64}$ CASPARI, Das Buch Hiob, pág. 93; $\alpha \lambda \lambda \mu \alpha$ es una planta herbácea anual hortense de la familia de las Portulacáceas que se usa como verdura. Olimpiodoro (Catena Graecorum Patrum, pág. 454) dice: Alima, herba quaedam est, ut aiunt, quae cito explet eum qui ea uescitur, et satietatem affert. Vulgata: et radix iuniperorum erat cibus eorum. Ita est etiam in Hebraeo, sed Graeci pro radice iuniperorum alima herbam illam quae famen tollere dicitur transtulerunt (apud ZúÑIGA, In Iob commentaria, pág. 423). La forma viene recogida en A. ForCELLINI et alii (Lexicon et Onomasticum totius latinitatis [Patavii: Typis seminarii, 1864, accesible en: http://www.lexica.linguax.com/ forc.php?searchedLG=auro]) como sinónimo de abrotonum (artemisia abrotanum), con rechazo de su identificación con auro, quod halimon Graeci uocant. 


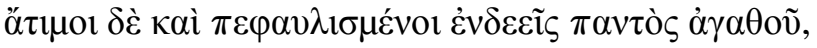

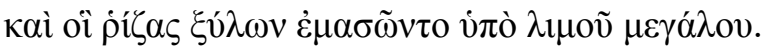

Interlineal: Frangentes auronem in sonante, qui auro erant eorum cibaria.

inhonorati autem et uiles habiti indigentes omnis boni; et qui radices lignorum mandebant pre fame magna.

Vulg.: et mandebant herbas et arborum cortices:

et radix iuniperorum erat cibus eorum.

- 30,7 घv̉ń $\chi \omega v>$ benesonantium ('armoniosos'). Traducción literal mediante mímesis etimológica del compuesto griego. Se relaciona con sonantem $(30,4)$, los sonidos que producen los arbustos movidos por el viento al pie de los cuales crece la hierba comestible de los miserables. La forma latina del adjetivo carece de precedentes ${ }^{65}$.

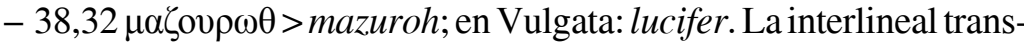
litera el griego $\mu \alpha \zeta o v \rho \omega \theta$, a su vez transliteración del hebreo מזרות 'constelaciones'. Quizás por la incertidumbre de su concreción quedó transliterado en la interlineal de Juan de Vergara ${ }^{66}$.

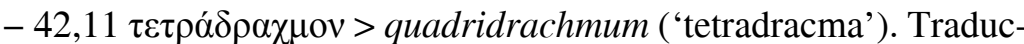
ción literal etimológica del primer elemento del compuesto griego y transliteración del segundo elemento.

La acuñación de neologismos latinos a partir de raíces presentes en romance, readaptadas para ser usadas como vocablos latinos, o surgidos de la propia imitación latina etimológica de los formantes griegos, asegura el literalismo absoluto de la interpretatio latina de Septuaginta y la forma latina más literal del texto bíblico griego. Los neologismos latinos acentúan el carácter intermediario de la traducción interlineal, el dominio lingüístico del latín de Juan de Vergara y la voluntad de acceder al sentido literal de la Escritura ${ }^{67}$.

\footnotetext{
${ }^{65}$ ZúÑIGA, In Iob commentaria, pág. 423.

${ }^{66}$ Olimpiodoro (Catena Graecorum Patrum, págs. 551-552) lo relaciona con la constelación del Canis Maior que sigue a Orión, el "Gran Cazador": Mazuroth uocem esse Hebraicam et significare syderum canem.

${ }^{67}$ Los complutenses conocían la doctrina escolástica, que siguiendo la tradición patrística que remonta a la escuela antioquena, otorga la primacía en la exégesis de 


\section{LA PRIMERA TRADUCCión LATINA DE SEPTUAGINTA DESDE VETUS Latina}

La fidelidad general a la Vulgata que sirvió de norma al proyecto de la Políglota, conforme al criterio textual de Cisneros de no corregir los textos sino editar sinfónicamente las diversas versiones bíblicas, salvaguardó los textos sin el emendare, corrigere, emaculare pretendido por Nebrija $^{68}$ :

Nouissime superueniens sanctus Hieronymus peritus in tribus linguis [...]: postea uero transtulit immediate bibliam de hebraeo in latinum sine astericis et obelis. Et hanc translationem nunc ubique utitur tota Romana ecclesia: licet non in omnibus libris. Et ipsius translatio merito caeteris antefertur: quia est uerborum tenacior et perspicuitate sententiae clarior (BPC, vol. I: iiiii(i)r).

No obstante, cualquier nueva traducción de un texto es una obra nueva que modifica en mayor o menor grado la antigua, pues traducir todos los aspectos del lenguaje es en sí mismo imposible ${ }^{69}$.

Las traducciones latinas interlineales de la Políglota fueron las primeras traducciones latinas de la Biblia griega desde la antigua Vetus Latina, cosa que las hace muy singulares como proyecto complementario de la edición trilingüe del texto bíblico y alternativa exegética al texto de Vulgata $^{70}$. Por ello, a pesar de que tras la muerte del cardenal la Inquisición

la palabra al sentido literal: Et ita etiam nulla confusio sequitur in sacra Scriptura, cum omnes sensus fundentur super unum, scilicet litteralem (TOMAE DE AQUINO, Summa Theologica I, q. 1 a. 10 ad 1, en: http://www.corpusthomisticum.org/ wintroes.html).

${ }^{68}$ G. Morocho Gayo, Estudios de Crítica textual (Murcia 2003) pág. 76; I. CARBAJosa, «A los 500 años de la Biblia Políglota Complutense. Enseñanzas de un gran proyecto editorial», Estudios Bíblicos 72:1 (2014) págs. 7-31.

${ }^{69}$ J. R. Busto SAiz, La traducción de Símaco en el Libro de los Salmos (Madrid

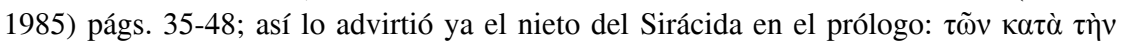

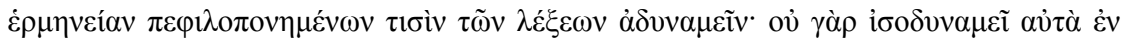

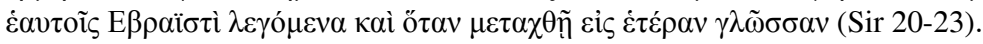

${ }^{70}$ Revilla Rico, La Políglota, pág. 95; N. Fernández Marcos, «The first Spanish Translation of the Septuagint», Estudios Bíblicos 68: 4 (2010) págs. 419-428: 421: «Notwithstanding, in my view, the most important is the interlinear version into Latin of the Septuagint, which, to my knowledge, is the first complete Latin translation of the Septuagint after the preserved Old Latin fragmentary»; G. AvENOZA, «Los estudios bíblicos 
quedó alarmada por la «herética» influencia que fomentó la Políglota Complutense y a pesar de que sus editores fueron acusados en muchos casos de herejía por su interpretación de los textos bíblicos en años posteriores, la traducción interlineal de Juan de Vergara tuvo una presencia no pequeña en el panorama de los estudios bíblicos europeos y sirvió de guía didáctica para el estudio de la Biblia griega.

En los siglos XVI-XVII se suceden las ediciones bíblicas que aprovechan el trabajo de la Políglota Complutense. Andreas Cratander reprodujo en 1526, sin mencionar su origen e incluso dando a entender que se debía a la ciencia de germanos, el texto de las interlineales complutenses en Basilea en 1526, reproducido también en posteriores impresiones (1550 y 1582) junto al texto griego de los LXX; Nicolaus Brylinger las incorporó a su Biblia Graeca et Latina de 1550, junto con el texto griego de la Aldina de 1518; aparece en la Políglota de Amberes, la llamada Políglota Regia (1568-1572), con leves retoques de Arias Montano; este último texto también se editó en la Políglota de Heidelberg de Francisco Vatablo $(1586,1599$ y 1616) y en la Políglota de París de Guido-Michel Le Jay (1629-1645) ${ }^{71}$.

\section{LA TRADUCCIÓN LATINA INTERLINEAL COMO INSTRUMENTO PEDAGÓGICO DE LA Políglota}

Toda traducción es un trasvase entre lenguas, un cruce de un camino de un lugar a otro. La tarea del traductor puede compararse a la de un modesto barquero que con su trabajo suprime el obstáculo lingüístico que separa al lector de la obra y su autor. Pero este trabajo, una vez efectuada la travesía, queda borrado de la superficie de las aguas. La traducción es un saber que se transmite con un objetivo concreto y la de Juan de Vergara tiene el fin de acercar el texto griego de los LXX a quien no sabe nada o poco griego (interpretatio 'intermediación'); lo hace por medio de un texto latino que

en la Península en romance antes de la Biblia Políglota Complutense: otra aproximación a la exégesis», en La Biblia Políglota Complutense, coord. A. Alvar Ezquerra (Alcalá 2016) págs. 77-86: 77: «La exégesis es un medio de acceso al texto bíblico, a través de una versión que lo haga inteligible y, por tanto, exégesis valdrá lo mismo que traducción».

${ }^{71}$ Walton, In Biblia Polyglota, págs. 105-108; Revilla Rico, La Políglota, págs. 109-110; I. J. García Pinilla, «La influencia de la Biblia Políglota Complutense», en La Biblia Políglota Complutense, coord. A. Alvar EzQuerra (Alcalá 2016) págs. 327-336. 
permita manejar los textos griegos y que sea tan fiel que, aun no entendiendo el texto griego, se pueda seguir sin dificultad. A la vez sirve como instrumento pedagógico para el aprendizaje del griego por medio del ejercicio de la retroversión lingüística. De este modo las versiones interlineales de la Políglota Complutense contribuyeron a mejorar la comprensión de Septuaginta y supusieron el primer gran trabajo filológico de comparación de modelos lingüísticos y literarios de la Edad Moderna ${ }^{72}$.

La traducción latina interlineal no pretende ser otra cosa que el propio texto griego en latín. La empresa de Cisneros proporcionó a los teólogos una herramienta básica para el estudio del texto bíblico y abrió la senda de la crítica textual bíblica a la filología y teología. Además, a pesar de que Vulgata actúa en la Políglota como texto aglutinante entre versiones bíblicas, y a pesar de que las traducciones interlineales mantienen un literalismo muy acentuado, estas fueron un campo en el que los editores encontraron libertad para poder abandonar lecturas de Vulgata, aprovechando las evidentes diferencias entre Septuaginta y el texto hebreo, y para ensayar nuevas lecturas e interpretaciones de los textos sagrados y fundamentar las críticas a Vulgata por deficiente traducción.

La relectura humanista del texto bíblico del AT, con las aportaciones originales y propias a la comprensión del texto bíblico que hemos expuesto en la traducción de los hápax legómena griegos, y la voluntad de literalismo que subyace en los neologismos latinos, reflejan, por otra parte, el profundo conocimiento escriturario de la Academia Complutense y el abierto espíritu humanista de Cisneros, que encomienda el texto sagrado a gramáticos teólogos, reconociendo que la Palabra de Dios se transmite en lenguaje humano sometido a la gramática ${ }^{73}$. Asimismo, en la traducción de los hápax griegos y la acuñación de neologismos latinos, queda expresa la primacía del sentido literal del texto bíblico. Con el abandono

${ }^{72}$ M. Vialon (ed.), La traduction à la Renaissance et à l'âge classique (Saint Étien 2001) pág. 8; L. Vegas Montaner, «Las versiones latinas en la Políglota Complutense», Estudios Bíblicos 72: 1 (2014) págs. 177-202: 201-202.

${ }^{73}$ SÁnchez Salor, «Las artes liberales y la Biblia», pág. 218; sobre la BPC como consecuencia del estudio literal (filológico e histórico) de la Biblia, $c f$. I. CARBAJOSA, «La confluencia de las exégesis judía y cristiana en la Biblia Políglota Complutense», en $L a$ Biblia Políglota Complutense, coord. A. Alvar EzQuerra (Alcalá 2016) págs. 105-115: 108-109. 
de lecturas de Vulgata a favor de traducciones innovadoras, queda expresa la voluntad de hacer el texto bíblico lo más inteligible posible y la primacía de la gramática para lograrlo ${ }^{74}$.

Aunque quizás ninguna de las partes de la Biblia Políglota Complutense puede adscribirse a un complutense concreto de modo absoluto, la traducción latina interlineal de Job de Juan de Vergara muestra la altura intelectual de este humanista español ya en su juventud. Sabemos, a pesar de que su obra posterior impresa fue escasa y de poca relevancia entre sus coetáneos, que su influencia entre los humanistas españoles de la primera mitad del siglo XVI no fue pequeña ${ }^{75}$. El arzobispo toledano Fonseca (1475-1534) dijo de Juan de Vergara, que fue su secretario ab epistulis:

Gloriari etiam solitus Vergaram se ut doctissimum hominem omnibus opibus et censibus anteferre, qui de laude eloquentiae cum aequalibus Bembo et Sadoleto, Leoni decimo Pont. ab epistolis, contendere $\operatorname{posset}^{76}$.

Las traducciones latinas interlineales de la Biblia Políglota Complutense fueron una contribución decisiva para la nueva sensibilidad renacentista hacia el texto bíblico, que es visto ahora por los humanistas como lenguaje humano sujeto a las leyes de la gramática, antes que como intangible texto revelado. La traducción latina interlineal de Job como inter-

${ }^{74}$ Lorenzo Valla en Ars grammatica resume el papel de la gramática en el organigrama del conocimiento así: «Toda doctrina tiene necesidad de la gramática, la gramática no necesita de ninguna y quien no la conoce se alimenta de polenta» ( $c f$. Aguadé NIETO, «La Biblia Políglota, los intelectuales y el poder», págs. 117-118).

${ }^{75}$ Lo refleja el epigrama que le dedicó Luis de la CADENA, Abad de la colegiata de Alcalá y Canciller de su universidad entre 1535-1558, poco después de la muerte de Juan de Vergara acaecida el 20 de febrero de 1557 (Menéndez Pelayo, Historia, pág. 707):

Vergara in uno natura fecit palam
praestare quantum illa homini posset boni.
Vergara in uno aemula mors fecit palam
auferre quantum rursus haec illi queat.
Mors ergo natura est major ac potentior,
quae quidquid illa struit, rapit ac diripit?
Minime: nam ille naturae dotibus
adjutus effecit, ne unquam posset mori.

${ }^{76}$ A. Sснотт, Hispaniae Bibliotheca seu De Academiis ac Bibliothecis (Francofurti 1608) págs. 552-554. 
pretatio de Septuaginta impresa junto a las translationes (la griega de los LXX y la de Vulgata de Jerónimo) y el texto fontal hebreo en la Políglota de Alcalá, contribuyó decisivamente a reintroducir el texto bíblico griego y ponerlo en valor.

Recibido: 04/08/2016

Aceptado: 25/02/2017 
